\begin{tabular}{|c|c|c|c|}
\hline \multirow{3}{*}{$\begin{array}{r}\text { Case Reports in } \\
\text { Gastroenterology }\end{array}$} & \multicolumn{2}{|c|}{ Case Rep Gastroenterol 2018;12:504-512 } & \multirow[b]{2}{*}{$\begin{array}{l}\text { Karger } \\
\text { Openaccess }\end{array}$} \\
\hline & $\begin{array}{l}\text { DOI: } 10.1159 / 000490658 \\
\text { Published online: August 28, } 2018\end{array}$ & $\begin{array}{l}\text { ( } 2018 \text { The Author(s) } \\
\text { Published by S. Karger AG, Basel } \\
\text { www.karger.com/crg }\end{array}$ & \\
\hline & $\begin{array}{l}\text { This article is licensed under th } \\
\text { International License (CC BY-NC) } \\
\text { Usage and distribution for commer }\end{array}$ & $\begin{array}{l}\text { nons Attribution-NonCommercial } 4.0 \\
\text { ger.com/Services/OpenAccessLicense). } \\
\text { uires written permission. }\end{array}$ & \\
\hline
\end{tabular}

\title{
Simultaneous Resection for Synchronous Double Primary Cancers of the Pancreas and the Liver
}

\author{
Tomohiko Taniai Koichiro Haruki Hiroaki Shiba Shinji Onda \\ Taro Sakamoto Katsuhiko Yanaga \\ Department of Surgery, The Jikei University School of Medicine, Tokyo, Japan
}

\section{Keywords}

Hepatocellular carcinoma Pancreatic ductal adenocarcinoma Simultaneous resection

\begin{abstract}
Simultaneous resection of synchronous hepatocellular carcinoma $(\mathrm{HCC})$ and pancreatic ductal adenocarcinoma (PDAC) is extremely rare. Case 1 is a 64 -year-old woman, who had undergone anterior resection for rectal cancer 3 years earlier was pointed out to have a cystic tumor in the pancreatic tail and a solitary tumor in the liver. CT revealed a hypovascular tumor in the pancreatic tail and a liver tumor with early enhancement. With a diagnosis of simultaneous HCC and PDAC, she underwent laparotomy, in which intraoperative frozen section examination of the liver was compatible with HCC. Therefore, she underwent hepatic resection as well as distal pancreatectomy and splenectomy. The patient received adjuvant chemotherapy with S-1 and remains well with no evidence of tumor recurrence as of 28 months after resection. Case 2 is a 73-year-old man with sustained viral response to antiviral treatment for hepatitis $C$ virus, who was pointed out to have a tumor in the pancreatic head and a solitary tumor in the liver. Gadoxetic acid-enhanced MRI exhibited enhancement compatible with HCC. With a diagnosis of concomitant HCC and PDAC, surgery was performed. Intraoperative frozen section examination was compatible with HCC, for which a pancreaticoduodenectomy was performed. The patient received adjuvant chemotherapy with $\mathrm{S}-1$ and remains well with no evidence of tumor recurrence as of 16 months after resection. In conclusion, we describe 2 cases of hepato-
\end{abstract}




\section{Case Reports in Gastroenterology}

Case Rep Gastroenterol 2018;12:504-512

DOI: $10.1159 / 000490658$

c 2018 The Author(s). Published by S. Karger AG, Basel www.karger.com/crg

Taniai et al.: Simultaneous Resection for Synchronous Double Primary Cancers of the Pancreas and Liver

pancreatectomy for synchronous double primary cancers of the pancreas and the liver, where exclusion of the liver tumor as a metastatic lesion from the pancreatic cancer is important.

(C) 2018 The Author(s)

Published by S. Karger AG, Basel

\section{Introduction}

Synchronous double primary cancers are increasing due to the improvement of imaging diagnosis and growing life expectancy. The most frequent malignant associations are ovarycolon, ovary-breast, and breast-breast [1]. However, synchronous double primary cancers of the pancreas and the liver are extremely rare. Both hepatic resection and pancreatic resection are so invasive that there have been few reports on simultaneous resection of the pancreas and liver, and the validity and safety of simultaneous resection remains controversial. We herein report 2 cases of simultaneous resection of synchronous double primary cancers of the pancreas and the liver.

\section{Case Report}

Case 1

A 64-year-old woman who had undergone anterior resection for sigmoid colon cancer 3 years earlier was pointed out to have a cystic tumor in the pancreatic tail and a solitary tumor in the liver. Laboratory data showed a slightly decreased hemoglobin level of $10.9 \mathrm{~g} / \mathrm{dL}$, slightly increased serum aspartate aminotransferase of $137 \mathrm{U} / \mathrm{L}$, and alanine aminotransferase of $54 \mathrm{U} / \mathrm{L}$. Tumor markers were as follows: serum carcinoembryonic antigen (CEA) 7.1 $\mathrm{ng} / \mathrm{mL}$, carbohydrate antigen (CA) 19-9 $87 \mathrm{U} / \mathrm{mL}$, and $\alpha$-fetoprotein (AFP) $4 \mathrm{ng} / \mathrm{mL}$. Computed tomography (CT) revealed a low-density tumor in the pancreatic tail (Fig. 1a) and a lowdensity tumor in segment 6 of the liver (Fig. 1c) with early enhancement (Fig. 1b). Gadoxetic acid-enhanced magnetic resonance imaging (MRI) exhibited a high-intensity tumor in the pancreatic tail in diffusion-weighted images (Fig. 1d). The liver tumor showed hypervascularity in early phase (Fig. 1e), which was identified as a defect in hepatocyte phase (Fig. 1f). With a diagnosis of hepatocellular carcinoma (HCC) and pancreatic cancer, surgery was performed. For a differential diagnosis of HCC and liver metastasis from pancreatic cancer, a partial liver resection was first performed for pathological diagnosis of the liver tumor (Fig. 2a, b). Intraoperative frozen section was compatible with HCC and, therefore, distal pancreatectomy and splenectomy with lymph node dissection were also performed (Fig. 2c). Pathological examination revealed HCC (Fig. 2d) and pancreatic ductal adenocarcinoma (PDAC) (Fig. 2e). After the operation, the patient developed chylous ascites and was treated by holding oral intake and with parenteral nutrition. Thereafter, the patient made a satisfactory recovery, and was discharged on postoperative day 34. She received adjuvant chemotherapy with S-1 for 6 months, and remains well with no evidence of tumor recurrence as of 28 months after resection.

\section{Case 2}

A 73-year-old man with sustained viral response to antiviral treatment for hepatitis C virus was pointed out during follow-up to have a tumor in the pancreatic head and a solitary tumor in the liver. Laboratory data showed elevated hemoglobin $\mathrm{A}_{1 \mathrm{c}}$ of $6.6 \%$, CEA of $3.1 \mathrm{ng} / \mathrm{ml}$, CA 19-9 of $1 \mathrm{U} / \mathrm{mL}$, AFP of $3.4 \mathrm{ng} / \mathrm{mL}$, and DUPAN-2 of 1,400 U/mL. CT revealed a low-density 
tumor in segment 7 of the liver in delayed phase (Fig. 3b) without early enhancement (Fig. 3a), and a low-density tumor in the pancreatic head (Fig. 3c) with dilatation of the distal main pancreatic duct (Fig. 3d). Enhanced MRI exhibited a low-intensity tumor in hepatocyte phase (Fig. 4b) without early enhancement (Fig. 4a). Endoscopic ultrasonography showed a heterogenous hypoechoic area in the uncinate process of the pancreas (Fig. 4c) and dilatation of the distal main pancreatic duct (Fig. 4d). With a diagnosis of HCC and pancreatic cancer, we first performed partial liver resection (Fig. 5a, b). Intraoperative frozen section examination was compatible with HCC and, therefore, subtotal stomach-preserving pancreaticoduodenectomy with lymph node dissection was performed (Fig. 5c). Pathological examination revealed HCC and PDAC (Fig. 5d, e). After the operation, the patient made a satisfactory recovery, and was discharged on postoperative day 17. He received adjuvant chemotherapy with S-1 for 6 months, and remains well with no evidence of tumor recurrence as of 16 months after resection.

\section{Discussion}

Multiple primary cancer was defined by Warren and Gates [2] in 1932 as follows: (i) each tumor must be distinct; (ii) each tumor must exhibit marked features of malignancy; and (iii) the probability of one lesion being a metastasis of the other must be excluded. The definition of synchronous and metachronous depends on the length of the interval between the first and second cancers. Synchronous is defined as different tumors found simultaneously or within 6 months, while metachronous signifies more than 6 months [3]. On the basis of these definitions, the current cases could be called synchronous double primary cancers.

The reported prevalence of multiple primary malignant neoplasms varies between 0.734 and $11.7 \%$ [4]. The treatment of synchronous double cancers generally relies on surgery; however, in surgically unresectable tumors, chemotherapy is considered [5]. There is no standard treatment for synchronous double primary malignancies [6]. For decision making of the treatment plan in patients with synchronous double cancers, it is important to estimate which tumor defines the prognosis of the patients. In the current cases, imaging diagnosis suggested HCC to be clinical stage I and PDAC as clinical stage III. Generally, the 5-year survival rate of PDAC stage III has a much poorer prognosis than that of HCC stage I. Eriguchi et al. [7] reported that the patients' prognosis of primary double cancers which include cancer of the pancreas and another organ depends on that of the pancreatic cancer. In the present cases, the patients' prognosis may be also defined by the pancreatic cancer. In order to determine treatment plans, it was important to assess the suitability of pancreatectomy. Tran et al. [8] reported the validity and safety of hepato-pancreatectomy, and concluded that less extensive hepato-pancreatectomy can be performed with reasonable morbidity and mortality with the exception of combined pancreaticoduodenectomy with hemihepatectomy. In the present cases, these operations (partial liver resection with distal pancreatectomy, and partial liver resection with subtotal stomach-preserving pancreaticoduodenectomy) were within the category of less extensive hepato-pancreatectomy. However, the result of their report is not completely applicable to the current cases. In their study, hepato-pancreatectomy was commonly performed for biliary tract carcinoma or pancreatic neuroendocrine tumor with liver metastasis, and not for double primary cancer of the pancreas and the liver. Thus, further studies are needed to clarify the validity and safety of hepato-pancreatectomy for synchronous double primary cancers of the pancreas and the liver. We described 2 cases of hepato-pancreatectomy 
for synchronous double primary cancers of the pancreas and the liver, where exclusion of the liver tumor as a metastatic lesion from the pancreatic cancer is important.

\section{Statement of Ethics}

Written informed consent was obtained from the patients for the publication of this case report and any accompanying images.

\section{Disclosure Statement}

The authors declare that they have no competing interest.

\section{Author Contributions}

T.T., K.H., H.S., S.O., and T.S. drafted the manuscript. K.Y. gave the final approval of the version to be published. All authors read and approved the final manuscript.

\section{References}

1 Irimie A, Achimas-Cadariu P, Burz C, Puscas E. Multiple primary malignancies-epidemiological analysis at a single tertiary institution. J Gastrointestin Liver Dis. 2010 Mar;19(1):69-73.

2 Warren S, Gates 0 . Multiple primary malignant tumors: a survey of the literature and a statistical study. Am J Cancer. 1932;16:1358-414.

3 Moertel CG, Dockerty MB, Baggenstoss AH. Multiple primary malignant neoplasms. I. Introduction and presentation of data. Cancer. 1961 Mar-Apr;14(2):221-30.

4 Demandante CG, Troyer DA, Miles TP. Multiple primary malignant neoplasms: case report and a comprehensive review of the literature. Am J Clin Oncol. 2003 Feb;26(1):79-83.

5 Kourie HR, Markoutsaki N, Roussel H, Rahmi G, Van der Stiegel M, Palazzo L, et al. Double pancreatic and gastric adenocarcinomas: a rare association. Clin Res Hepatol Gastroenterol. 2013 Dec;37(6):e137-40.

6 Sun JJ, Yang TB, Yang YH, Liu WF, Song JX. Synchronous double primary malignancies of the liver and kidney: A case report. Oncol Lett. 2016 Mar;11(3):2057-60.

7 Eriguchi N, Aoyagi S, Hara M, Okuda K, Tamae T, Fukuda S, et al. Synchronous or metachronous double cancers of the pancreas and other organs: report on 12 cases. Surg Today. 2000;30(8):718-21.

8 Tran TB, Dua MM, Spain DA, Visser BC, Norton JA, Poultsides GA. Hepato-pancreatectomy: how morbid? Results from the national surgical quality improvement project. HPB (Oxford). 2015 Sep;17(9):763-9. 


\section{Case Reports in Gastroenterology}
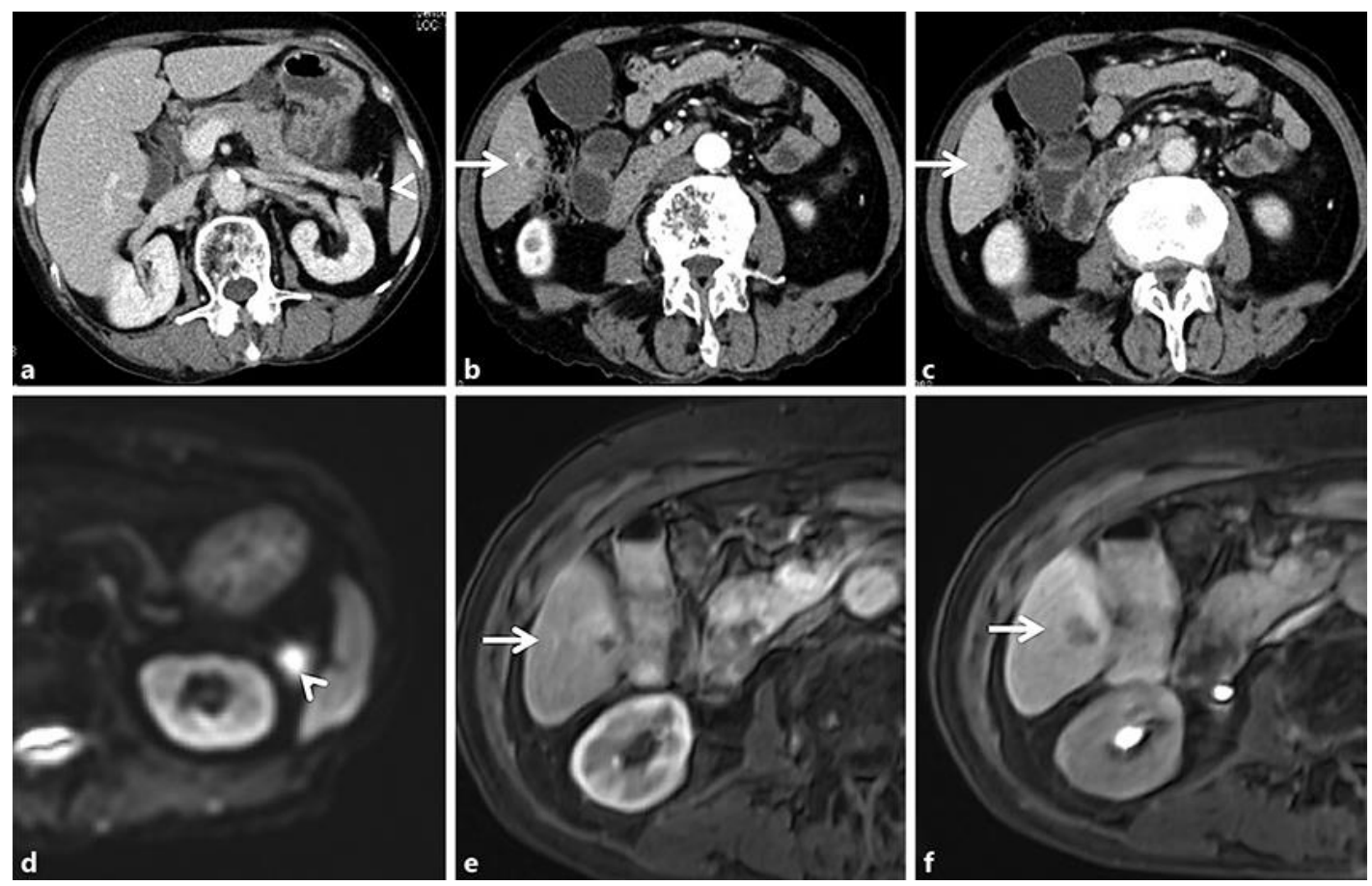

Fig. 1. Computed tomography revealed a low-density tumor in the pancreatic tail (a, arrowhead) and a lowdensity tumor in segment 6 of the liver (c, arrow) with early enhancement (b, arrow). Gadoxetic acid-enhanced magnetic resonance imaging exhibited a high-intensity tumor in the pancreatic tail in diffusionweighted images (d, arrowhead). The liver tumor showed a vascularity in early phase (e, arrow), which was defective in hepatocyte phase (f, arrow). 


\section{Case Reports in Gastroenterology}

\begin{tabular}{l|l}
\hline Case Rep Gastroenterol 2018;12:504-512 \\
\hline DOI: 10.1159/000490658 & $\begin{array}{l}\text { @ 2018 The Author(s). Published by S. Karger AG, Basel } \\
\text { www.karger.com/crg }\end{array}$ \\
\hline
\end{tabular}

Taniai et al.: Simultaneous Resection for Synchronous Double Primary Cancers of the Pancreas and Liver
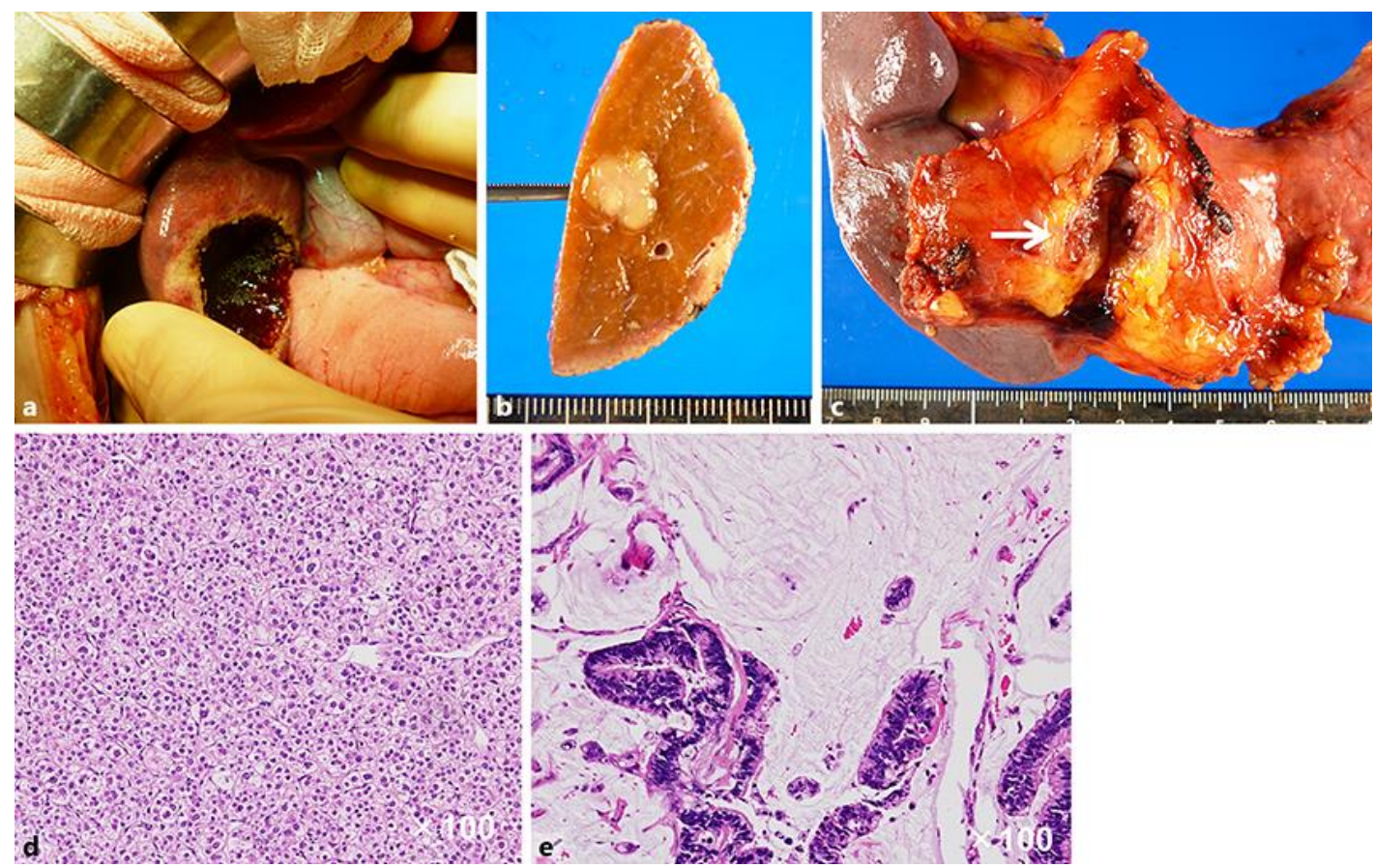

Fig. 2. The resected specimen from segment 6 in the liver (a) showed expansive growth (b). The pancreatic tumor was hard and located in the body of the pancreas (c, arrow). Pathological examination revealed hepatocellular carcinoma (d) and pancreatic ductal adenocarcinoma (e), respectively. 

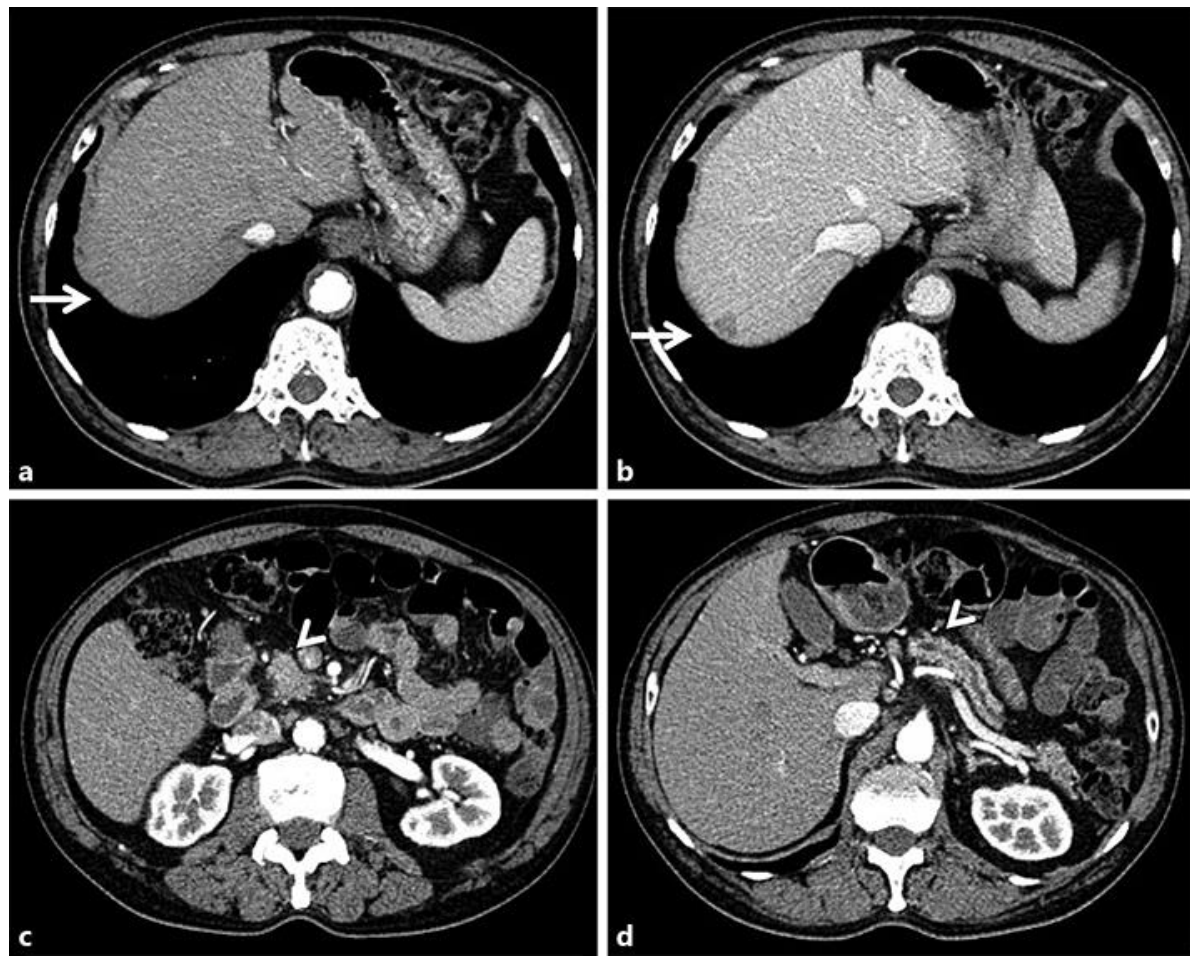

Fig. 3. Computed tomography revealed a low-density tumor in segment 7 of the liver in delayed phase (b, arrow) without early enhancement (a, arrow) and a low-density tumor in the pancreatic head (c, arrowhead) with dilatation of the distal main pancreatic duct (d, arrowhead). 

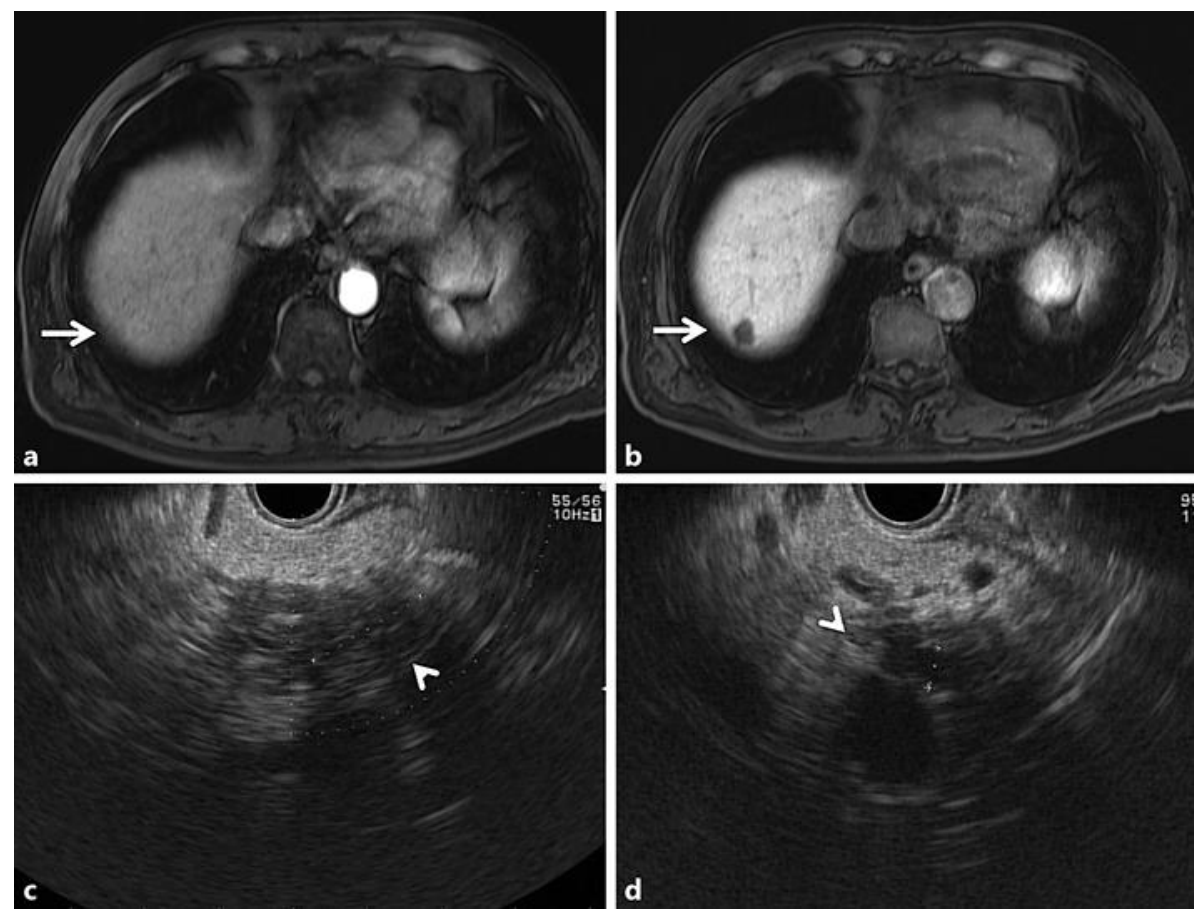

Fig. 4. Gadoxetic acid-enhanced magnetic resonance imaging exhibited a low-intensity tumor in hepatocyte phase (b, arrow) without early enhancement (a, arrow). Endoscopic ultrasonography showed a heterogenous hypoechoic area in the uncinate process of the pancreas (c, arrowhead) and dilatation of the distal main pancreatic duct (d, arrowhead). 


\section{Case Reports in Gastroenterology}

Case Rep Gastroenterol 2018;12:504-512

DOI: $10.1159 / 000490658$

(c) 2018 The Author(s). Published by S. Karger AG, Basel www.karger.com/crg

Taniai et al:: Simultaneous Resection for Synchronous Double Primary Cancers of the Pancreas and Liver
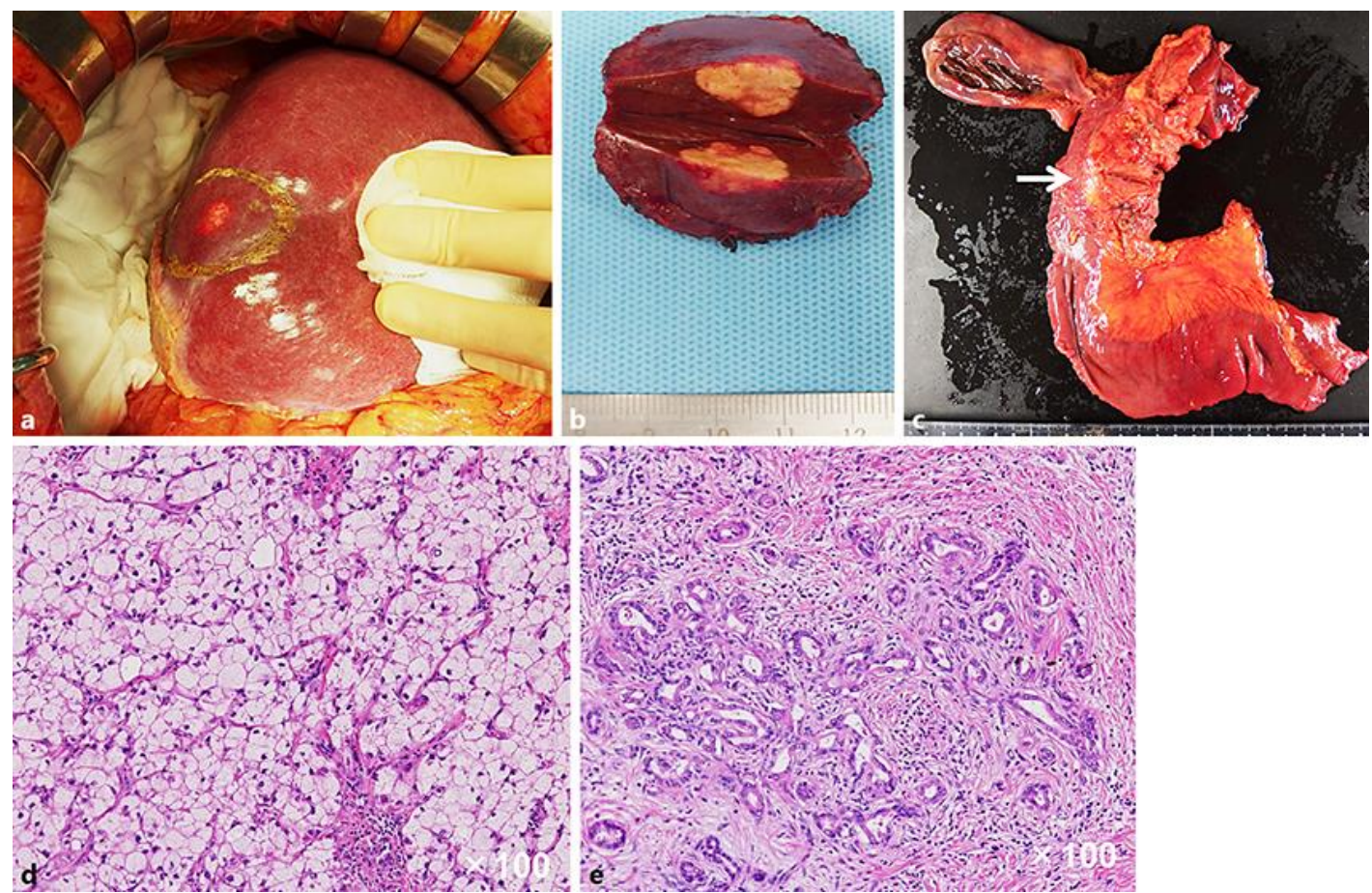

Fig. 5. The liver tumor was located in segment 7 of the liver (a). The resected specimen of the liver showed expansive tumor growth (b). The pancreatic tumor was located in the uncinate process of the pancreas (c, arrow). Pathological examination revealed hepatocellular carcinoma (d) and pancreatic ductal adenocarcinoma (e), respectively. 